\title{
INVESTIGATION OF THE TRANSIENT AND STEADY STATE OPERATIONS OF TWO LINE START PERMANENT MAGNET MOTORS (LSPMMS) WITH DIFFERENT ROTOR CONFIGURATIONS
}

\author{
J. C. Asogwa ${ }^{1, *}$ and E. S. Obe ${ }^{2}$ \\ 1, ENERgy COMMISSION OF Nigeria, ABUJA, NIGERIA \\ 2. Department of Electrical EngineERING, University of Nigeria, NsuKKA, ENUGu State, NIGERIA \\ E-mail addresses: ${ }^{1}$ jasogwa@yahoo.com, ${ }^{2}$ simon.obe@unn.edu.ng
}

\begin{abstract}
This paper investigates the transient and steady state operations of two Line Start Permanent Magnet Motors (LSPMMs) with different rotor types. The calculations showed that both designs can reach a higher efficiency than comparable induction motorsof the same size. The loading capability of the Surface Permanent Magnet (SPM) rotor is better than the Interior Permanent Magnet (IPM) rotor on asynchronous rotation as it has lesser torque ripples. However, IPM rotor had less flux leakage and copper losses at the synchronous operation under the same loading conditions.The results of the investigation also show that IPM motor attains a higher speed responses than SPM motor but SPM motor synchronizes faster than the IPM motor under the same loading conditions. During the asynchronous period, the chracteristics of both machines display similar features at a lower load torque less than $50 \mathrm{~N}-\mathrm{m}$. The ripple contents of IPM is greater than that of SPM as can be observed in the run-up speed characteristics where IPM shows spontaneous overshoot. The pull out torque for SPM and IPM occurred at the time of 6 and 10 second respectively with same load increments.
\end{abstract}

Keywords: synchronous, asynchronous, motor, permanent magnet,torque

\section{INTRODUCTION}

Since the advent of AC machines, synchronous machines have been very popular in electrical power generation because of its high efficiency, power factor and simplicity of control. Conventional synchronous machines require a DC rotor field excitation. On the other hand, a PM synchronous machine utilizes a permanent magnet to generate the rotor flux. Therefore, losses associated with the rotor are absent in a PM synchronous machine. Because of this, the PM machine has the highest efficiency among all $A C$ machines.

Furthermore, due to the advancements of high energy-density permanent magnet material, research on the PM synchronous machine and its control techniques are becoming ever more prevalent today [2-4]. In the recent past, technological advancement led to the discovery of Line Start Permanent Magnet
Motors (LSPMM) that have some performance and efficiency advantages over induction motors. LSPMM have a stator winding configuration similar to the three-phase induction motors, but they use permanent magnets in the rotor instead of a squirrel cage or wound rotor. The LSPMM maintains same speed in synchronism with the stator rotating field, and therefore the rotor speed is equal to the rotating magnetic field speed.

The key advantage of the LSPMM is that no excitation power is required for the rotor and therefore its efficiency is higher compared to the induction motor. Early LSPMM, besides being very expensive, suffered from the tendency of the magnets to be demagnetized by the high stator currents during starting; much improved versions using rare-earth magnets have been developed since the 1970 s to overcome these problems $[2,4]$. 
Induction Motors (IMs) have been widely applied in industry because of the low manufacturing cost and the robust structure. The induced current in the rotor cage bars will generate large copper loss and lower the motor efficiency as a result of the inherent slip in the operation of IMs. In order to save electric energy, the needs of high efficiency motors have grown in recent years, and the Line Start Permanent Magnet Motors (LSPMMs) are attractive alternatives to the IMs. The structure of LSPMM is similar to the IM but with the permanent magnets inserted in the rotor. Hence the LSPMM combines IMs and Permanent Magnet Synchronous Motors (PMSMs) structural features, and is able to start by the cage torque as IMs but finally rotates at synchronous speed with the flux that is provided by the magnets [1][2].

With the synchronous operation, the rotor copper losses of the LSPMMs are reduced significantly and higher efficiency is reached at the steady state. Unfortunately, an inverse direction torque generated from the permanent magnets seriously decreases the starting and asynchronous loading capability [4]. Therefore, the performance of LSPMMs is deeply influenced by the collocations of magnets and squirrel cages. From the point of the magnet arrangements, the LSPMMs can be separated into two types. The first type is the interior magnet design which has embedded magnets inside the rotor iron. This type is a conventional design of LSPMMs with the robust structure and is hard to be demagnetized due to the protection of squirrel cages. The second type is the surface-magnet design which has surface mounted magnets at the rotor. The main advantage of the surface-magnet design is easier manufacturing than those alternatives using inserted magnets. Moreover, this second type can provide larger permanent magnet synchronous torque via the shorter distance between the magnets and the stator winding.

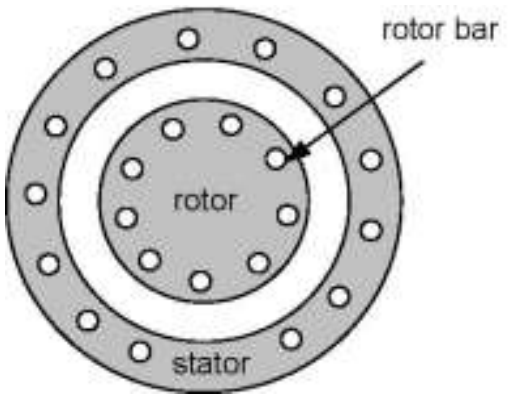

(a)
Fig. 1 compares the general constructional features of Induction motors, SPM and IPM motors. In order to analyze the effects of magnet configurations for LSPMMs, Fig. 1(a) shows the structures of an induction motor and two widely-used PM motors. The magnets of the surface-mounted PM (SPM) motor in Fig. 1 (b) are attached on the surface of the rotor, whereas those of the interior-buried PM (IPM) motor are buried inside as shown in Fig. 1 (c).

The magnets of SPM motors need to be fixed on the rotor surface using adhesive, thus mechanical strength is weaker than IPM motors especially in the high speed region. The magnetic flux in the rotor of the induction motor is induced by the rotation of the stator magnetic field.

The IPM motor has high efficiency and high torque because it utilizes both magnet and reluctance torques caused by the magnetic saliency [2].

The evolution of line-start PM motors began in the early 1940s when the hysteresis motor was introduced by Teare [5]. The insertion of PMs into the rotor bridge of a double-cage induction motor was reported by Alger [6] in the 1950s. The hysteresis motor was the forerunner of the modern Permanent Magnet Motor (PMM). Rahman [7] made seminal contributions to the hysteresis $(\mathrm{B}-\mathrm{H})$ phenomenon of semihard (low BHmax) energy product materials. He investigated the fundamental physics of ac hysteresis in ferromagnetic materials. Normally, hysteresis causes energy losses, thus it must be eliminated or at least minimized. However, in hysteresis motors, the energy within the $\mathrm{B}-\mathrm{H}$ hysteresis loop area is used to develop the driving torque. He started constructing circumferential flux hysteresis motors using $17-36 \%$ silicon cobalt steel metallic alloys for hysteresis rings for rotors in the 1960s[7] .

Fig.1: Rotor structures of the IM and two LSPMM alternative models: (a) the original IM, (b) the surface type and (c) the interior type. 
The developed hysteresis power is proportional to hysteresis equivalent resistance $R h$. $R h$ is directly proportional to the slip of the motor. At start, $R h$ is maximum, and it is zero at synchronous speed. Thus, $R h$ is considered an ideal starter property. Hence, a hysteresis motor is a self-starting synchronous motor irrespective of load and inertia as long as the ac supply is maintained. When the ac voltage supply is switched off, the hysteresis loop collapses. From this perspective, the hysteresis motor is called a temporary PM self-starting synchronous motor. In a practical hysteresis rotor ring made of low coercive force alloys, there is some finite conductivity. That was one of the reasons for introducing saturistor hysteresis bars into multi-cage induction motors. Once the motor is synchronized, induction torque disappears and the motor exclusively runs by hysteresis torque alone [8]. A synchronously run hysteresis motor is effectively a PM motor. Sustained and extensive research, development, analysis, control and applications of the PMSM have been progressing by leaps and bounds for the past two decades. Merrill [9] introduced a PMM using AlNiCo-5 in 1955. Binns, Barnard and Jabber [10] presented a series of flux-focused PMM using ferrite PM materials in the late 1970s. Rahman [11] designed and built the first 45-kW high-efficiency IPM motor utilizing NdBFe magnets in 1982. Rahman, Little, and Slemon [12] provided analytical models for PMM in 1985. Jahns [13] incorporated the flux-weakening regime in 1987. Sebastian and Slemon [14] presented inverterfed PMM with position sensors in 1987. Consoli and Vagati [15] extended design criteria of PMM for field weakening operation in the 1990s. Zhou and Rahman [16] presented the finite element analysis of the PMM motor incorporating field and circuit coupling in 1994. Direct and indirect position and sensorless controls of the PMM have been introduced by many authors, including Lorentz [17], Sul [18], and Rahman [19], since the year 2000s.

\section{MATERIALS AND METHODS}

The simulation was carried out with the help of embedded Matlab [20] function tool which provided easy analysis of the graphical results as were obtained. The no-load conditions are simulated in order to outline the flux characteristics provided by the two different rotor designs. Moreover, a constant loading torque is given to the LSPMMs from zero speed to analyze the asynchronous loading and synchronization capabilities of the two rotor types.
Finally, with consideration to some applications that have light loads at the transient state but heavy loads at the steady state, the loading capability of LSPMMs under synchronous operation was also investigated. The motors simulated in this work are operated under the rating voltage $230 \mathrm{~V}$ and frequency of $50 \mathrm{Hertz}$.

\section{MODELING}

Thus, we can express the inductances of the machine in matrix form as

$$
[L]=\left[\begin{array}{l}
L_{\text {asas }} M_{\text {asbs }} M_{\text {ascs }} M_{\text {asfd }} \\
M_{\text {bsas }} L_{\text {bsss }} M_{\text {bscs }} M_{\text {bsfd }} \\
M_{\text {csas }} M_{\text {csbs }} L_{\text {cscs }} M_{\text {csfd }} \\
M_{\text {fdas }} M_{\text {fdbs }} M_{\text {fdcs }} L_{\text {fdfd }}
\end{array}\right]
$$

Where Lasas, Lbsbs, LcscS, and Lfdfd are the selfinductance of the machine while other variables in equation (1) are the mutual inductances.

The relation between the flux linkages, inductances and currents is given as:

$$
[\lambda]=[L] \times[i]
$$

Thus, the flux: linkage in phases $a, b, c$ and field windings are given as:

$$
\left[\begin{array}{l}
\lambda_{a s} \\
\lambda_{b s} \\
\lambda_{c s} \\
\lambda_{f d}
\end{array}\right]=\left[\begin{array}{c}
\mathrm{L}_{\text {asas }} \mathrm{M}_{\text {asbs }} \mathrm{M}_{\text {ascs }} \mathrm{M}_{\text {asfd }} \\
\mathrm{M}_{\mathrm{bsas}} \mathrm{L}_{\mathrm{bsbs}} \mathrm{M}_{\mathrm{bscs}} \mathrm{M}_{\mathrm{bsfd}} \\
\mathrm{M}_{\mathrm{csas}} \mathrm{M}_{\mathrm{csbs}} \mathrm{L}_{\mathrm{cscs}} \mathrm{M}_{\mathrm{csf}} \\
\mathrm{M}_{\mathrm{fdas}} \mathrm{M}_{\mathrm{fdbs}} \mathrm{M}_{\mathrm{fdcs}} \mathrm{L}_{\mathrm{fdd}}
\end{array}\right] \times\left[\begin{array}{c}
\mathrm{i}_{\mathrm{as}} \\
\mathrm{i}_{\mathrm{bs}} \\
\mathrm{i}_{\mathrm{cs}} \\
\mathrm{i}_{\mathrm{fd}}
\end{array}\right]
$$

Then, we can also write flux linkage for any phase individually as:

$$
\begin{aligned}
& \lambda_{\mathrm{as}}=\mathrm{L}_{\mathrm{asas}} \mathrm{i}_{\mathrm{as}}+\mathrm{M}_{\mathrm{asbs}} \mathrm{i}_{\mathrm{bs}}+\mathrm{M}_{\mathrm{ascs}} \mathrm{i}_{\mathrm{cs}}+\mathrm{M}_{\mathrm{asfd}} \mathrm{i}_{\mathrm{fd}} \\
& \lambda_{b s}=L_{b s a s} i_{a s}+M_{b s b s} i_{b s}+M_{b s c s} i_{c s}+M_{b s f d} i_{f d} \\
& \lambda_{\text {cs }}=L_{\text {csas }} i_{\text {as }}+M_{\text {csbs }} i_{b s}+M_{c s c s} i_{c s}+M_{c s f d} i_{f d} \\
& \lambda_{\text {fd }}=L_{\text {fdas }} i_{\text {as }}+M_{\text {fdbs }} i_{b s}+M_{\text {fdcs }} i_{c s}+M_{f d f d} i_{f d}
\end{aligned}
$$

The flux linkage in the stator winding due to the permanent magnet in the rotor is given as:

$$
[\lambda]=\left[\begin{array}{c}
\lambda_{\text {asfd }} \\
\lambda_{\text {bsfd }} \\
\lambda_{\text {csfd }}
\end{array}\right]=\left[\begin{array}{c}
\lambda_{\mathrm{m}} \sin \theta_{\mathrm{r}} \\
\lambda_{\mathrm{m}} \sin \left(\theta_{\mathrm{r}}-\frac{2 \pi}{3}\right) \\
\lambda_{\mathrm{m}} \sin \left(\theta_{\mathrm{r}}+\frac{2 \pi}{3}\right)
\end{array}\right]
$$

Thus, we can rewrite the equations ( $4-6)$ as follows:

$$
\begin{aligned}
\lambda_{\mathrm{as}}=\mathrm{L}_{\mathrm{asas}} \mathrm{i}_{\mathrm{as}}+ & \mathrm{M}_{\mathrm{asbs}} \mathrm{i}_{\mathrm{bs}}+\mathrm{M}_{\mathrm{ascs}} \mathrm{i}_{\mathrm{cs}}+\lambda_{\mathrm{m}} \\
\lambda_{\mathrm{bs}}=\mathrm{M}_{\mathrm{bsas}} \mathrm{i}_{\mathrm{as}}+ & L_{\mathrm{bsbs}} \mathrm{i}_{\mathrm{bs}}+\mathrm{M}_{\mathrm{bscs}} \mathrm{i}_{\mathrm{cs}} \\
& +\lambda_{\mathrm{m}} \sin \left(\theta_{\mathrm{r}}-\frac{2 \pi}{3}\right) \\
\lambda_{\mathrm{cs}}=\mathrm{M}_{\mathrm{csas}} \mathrm{i}_{\mathrm{as}}+ & \mathrm{M}_{\mathrm{csbs}} \mathrm{i}_{\mathrm{bs}}+L_{\mathrm{cscs}} \mathrm{i}_{\mathrm{cs}} \\
+ & \lambda_{\mathrm{m}} \sin \left(\theta_{\mathrm{r}}+\frac{2 \pi}{3}\right)
\end{aligned}
$$

In the matrix form we can write the equations (9 11) as: 


$$
\begin{array}{r}
{\left[\begin{array}{l}
\lambda_{\mathrm{as}} \\
\lambda_{\mathrm{bs}} \\
\lambda_{\mathrm{cs}}
\end{array}\right]=\left[\begin{array}{l}
L_{a s a s} M_{a s b s} M_{a s c s} \\
M_{b s a s} L_{b s b s} M_{b s c s} \\
M_{c s a s} M_{c s b s} L_{c s c s}
\end{array}\right]\left[\begin{array}{l}
\mathrm{i}_{\mathrm{as}} \\
\mathrm{i}_{\mathrm{bs}} \\
\mathrm{i}_{\mathrm{cs}}
\end{array}\right]} \\
+\lambda_{m}\left[\begin{array}{c}
\sin \theta_{\mathrm{r}} \\
\sin \left(\theta_{\mathrm{r}}-\frac{2 \pi}{3}\right) \\
\sin \left(\theta_{\mathrm{r}}+\frac{2 \pi}{3}\right)
\end{array}\right]
\end{array}
$$

The voltage equation for the permanent magnet synchronous motor can be written as the synchronous machine equations without the damper winding and field current dynamics.

$$
\begin{aligned}
& \mathrm{V}_{\mathrm{as}}=\mathrm{r}_{\mathrm{as}} \mathrm{i}_{\mathrm{as}}+\frac{\mathrm{d} \lambda_{\mathrm{as}}}{\mathrm{dt}} \\
& \mathrm{V}_{\mathrm{bs}}=\mathrm{r}_{\mathrm{bs}} \mathrm{i}_{\mathrm{bs}}+\frac{\mathrm{d} \lambda_{\mathrm{bs}}}{\mathrm{dt}} \\
& \mathrm{V}_{\mathrm{cs}}=\mathrm{r}_{\mathrm{cs}} \mathrm{i}_{\mathrm{cs}}+\frac{\mathrm{d} \lambda_{\mathrm{cs}}}{\mathrm{dt}}
\end{aligned}
$$

Equations (13 - 15) can be written in matrix form as:

$$
\left[\begin{array}{l}
V_{a s} \\
V_{b s} \\
V_{c s}
\end{array}\right]=\left[\begin{array}{lll}
r_{a s} & 0 & 0 \\
0 & r_{b s} & 0 \\
0 & 0 & r_{c s}
\end{array}\right]\left[\begin{array}{c}
i_{a s} \\
i_{b s} \\
i_{c s}
\end{array}\right]+P\left[\begin{array}{c}
\lambda_{a s} \\
\lambda_{b s} \\
\lambda_{c s}
\end{array}\right]
$$

Where the operator $\mathrm{p}=\mathrm{d} / \mathrm{dt}$ and $\lambda$. is the flux linkage.

$$
\begin{array}{r}
{\left[\begin{array}{l}
\lambda_{\mathrm{as}} \\
\lambda_{\mathrm{bs}} \\
\lambda_{\mathrm{cs}}
\end{array}\right]=\left[\begin{array}{l}
L_{a s a s} M_{a s b s} M_{a s c s} \\
M_{b s a s} L_{b s b s} M_{b s c s} \\
M_{c s a s} M_{c s b s} L_{c s c s}
\end{array}\right]\left[\begin{array}{l}
\mathrm{i}_{\mathrm{as}} \\
\mathrm{i}_{\mathrm{bs}} \\
\mathrm{i}_{\mathrm{cs}}
\end{array}\right]} \\
+\lambda_{m}\left[\begin{array}{c}
\sin \theta_{\mathrm{r}} \\
\sin \left(\theta_{\mathrm{r}}-\frac{2 \pi}{3}\right) \\
\sin \left(\theta_{\mathrm{r}}+\frac{2 \pi}{3}\right)
\end{array}\right]
\end{array}
$$

\section{Torque expression of PMSM}

The expression for the electromagnetic torque developed by the machine can be obtained from the component of the input power that is transferred across the air gap.

The total input power into the machine is given by

$$
P_{\text {in }}=V_{a} i_{a}+V_{b} i_{b}+V_{c} i_{c}
$$

\section{SIMULATION}

The following equations19 - 28 were used with the torque and mechanical equations to carry out the simulations for the direct - on - line starting of the permanent magnet machines.

$$
\begin{aligned}
& V_{q s}=r_{s} I_{q s}+P \lambda_{q s}+\omega_{r} \lambda_{d s} \\
& V_{d s}=r_{s} I_{d s}+P \lambda_{d s}-\omega_{r} \lambda_{q s} \\
& V_{o s}=r_{s} I_{o s}+P \lambda_{o s} \\
& V_{q r}=r_{q r} I_{q r}+P \lambda_{q r} \\
& V_{d r}=r_{d r} I_{d r}+P \lambda_{d r}
\end{aligned}
$$

\begin{tabular}{|c|c|c|}
\hline \multicolumn{3}{|c|}{ 3-phase IPMM } \\
\hline $\mathrm{S} / \mathrm{No}$ & Parameter & Quantity \\
\hline 3 & Ld & $58 \mathrm{mH}$ \\
\hline 4 & $\mathrm{Lq}$ & $86 \mathrm{mH}$ \\
\hline 5 & Lls & $14 \mathrm{mH}$ \\
\hline 6 & Rs & $1.301 \Omega$ \\
\hline 7 & Lldr & $7.449 \mathrm{mH}$ \\
\hline 8 & Llqr & $7.449 \mathrm{mH}$ \\
\hline 9 & J & $0.42 \mathrm{kgm}^{-3}$ \\
\hline 10 & $\mathrm{Rdr}$ & $0.957 \Omega$ \\
\hline 11 & Rqr & $1.912 \Omega$ \\
\hline 12 & $\lambda_{m}$ & $0.8 \mathrm{~Wb}$ turn \\
\hline
\end{tabular}

$\mathrm{V}_{\mathrm{qr}}$ and $\mathrm{V}_{\mathrm{dr}}$ are the quadrature axis and direct axis voltages referred of the rotor cage respectively.
Where;

$$
\begin{aligned}
& \lambda_{q s}=I_{q s} L_{l s}+L_{m q}\left(I_{q s}+I_{q r}\right) \\
& \lambda_{d s}=I_{d s} L_{l s}+L_{m d}\left(I_{d s}+I_{d r}\right)+\lambda_{m} \\
& \lambda_{o s}=L_{l s} I_{o s} \\
& \lambda_{q r}=I_{q r} L_{l q r}+L_{m q}\left(I_{q s}+I_{q r}\right) \\
& \lambda_{d r}=I_{d r} L_{l d r}+L_{m d}\left(I_{d s}+I_{d r}\right)
\end{aligned}
$$

Table 1: The Parameters of 2-pole $4 \mathrm{hp}, 230 \mathrm{~V}, 50 \mathrm{~Hz}$,

Table2: The Parameters of 2-pole 4hp, 230V, 50Hz,

\begin{tabular}{lll} 
& \multicolumn{2}{c}{ 3-phase SPMM } \\
\hline S/No & Parameter & Quantity \\
\hline 1 & Ld & $58 \mathrm{mH}$ \\
2 & Lq & $86 \mathrm{mH}$ \\
3 & Lmd & Ld - Lls \\
4 & Lmq & Lq - Lls \\
5 & Lls & $6.5 \mathrm{mH}$ \\
6 & Rs & $1.41 \Omega$ \\
7 & Lldr & $0.132 \mathrm{mH}$ \\
8 & Llqr & $0.132 \mathrm{mH}$ \\
9 & J & $0.42 \mathrm{kgm}$ \\
10 & Rdr & $0.054 \Omega$ \\
11 & Rqr & $0.108 \Omega$ \\
12 & $\lambda_{m}$ & $0.8 \mathrm{~Wb}$ turn \\
& &
\end{tabular}

\section{RESULTS AND DISCUSSIONS}

The results show that the LSPMMs have high efficiency at the synchronous rotation but poor loading and synchronization capabilities during the asynchronous period.

The asynchronous rotation when the load torque is below $50 \mathrm{~N}-\mathrm{m}$ shows that both machines behave alike but the excitation torque of the Interior Permanent Motor (IPM) is greater than the Surface Permanent Motor (SPM) during the asynchronous period as shown in the overshoot in Figure 2 below. It can also be verified from the simulation plot of Figure 2 that the SPM attains synchronism faster but can only withstand a maximum load of $75 \mathrm{~N}-\mathrm{m}$ at maximum 
time of 6seconds as can be verified in Figure 3. The IPM type can synchronize at a later time and holds on to a load of $125 \mathrm{~N}-\mathrm{m}$ at a maximum time of 10 seconds before losing synchronism as shown in Figure 4.

The results also point out the fact that surfacemagnet design has a smaller asynchronous torque than that of the interior type. For the surface type ones, the smaller size of the squirrel cage will decrease the skin effect of the rotor cage bars and reduce the rotor induced current and the cage torque. The results also show that the synchronization capability of the surface PMM is better than those of the interior PMM as it is characterized by less ripple effect.

For greater emphasis, the torque, currents and excitation characteristics of both machines are displayed graphically in the plot sheets that were obtained from the simulation results as shown below. The results realized enabled us to draw conclusions

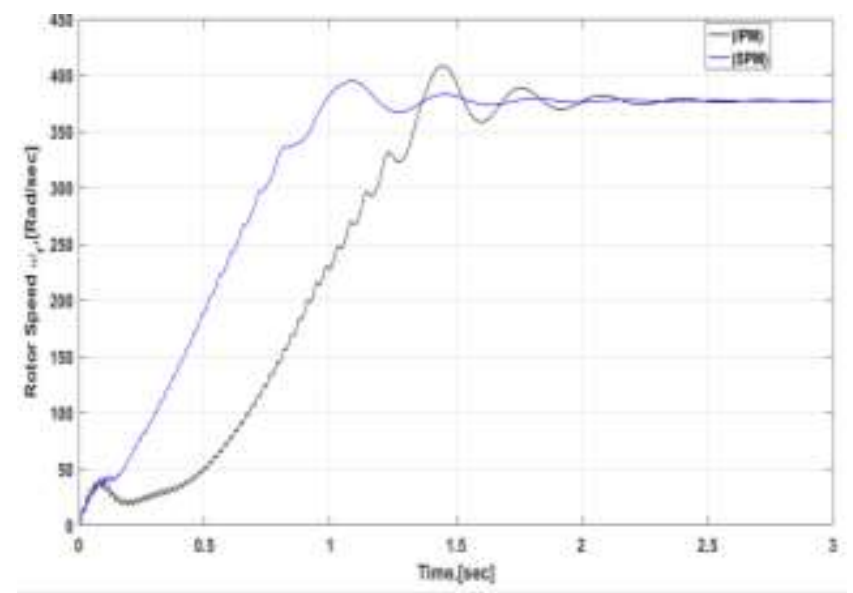

Figure 2: The Rotor Speed Response of SPM \& IPM under different Loading Conditions

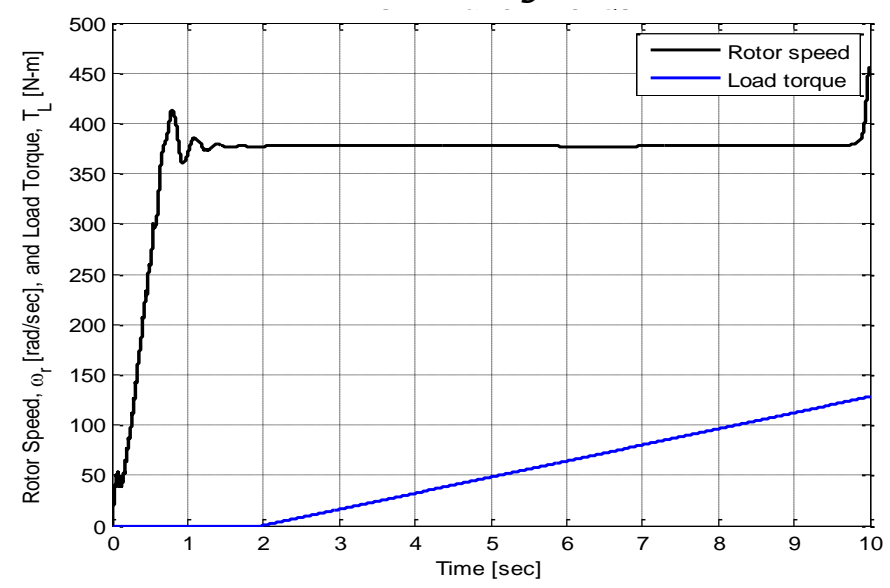

Figure 4: The Rotor Speed Response of IPM under different Loading Conditions on the inherent characteristics of the machines which give insights on the choice of the machine that will be able to perform a defined function in relation to the torque load characteristics. It is also important to restate that such an insight given by the simulation results will further be of a necessity in the rotor design and configuration in a case where the desired and defined machine functions ought to be realized with the highest probability of achieving precision, greater efficiency, stability and reliability during its operations. Figure 5 indicates the induced rotor currents of SPM types at synchronous speed under different loading conditions. Since there is smaller difference of reactance of the $d$ and $q$-axis, the excitation torque and induced current of the surface type at the steady state is smaller than that of the interior type. From Figure 5 and 6 , it is obvious that the induced current of the surface type is closer to zero and decreases the copper losses with synchronous operation.

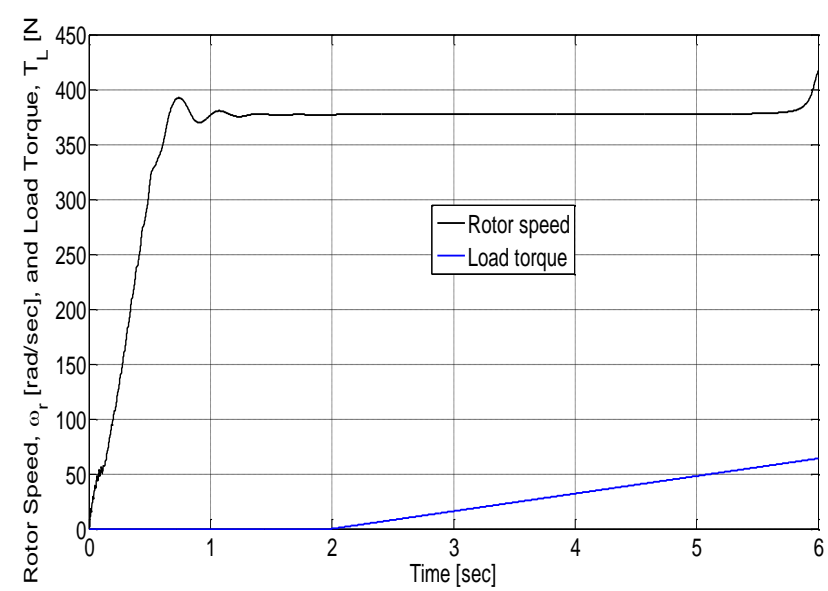

Figure 3: The Rotor Speed Response of SPM under different Loading Conditions

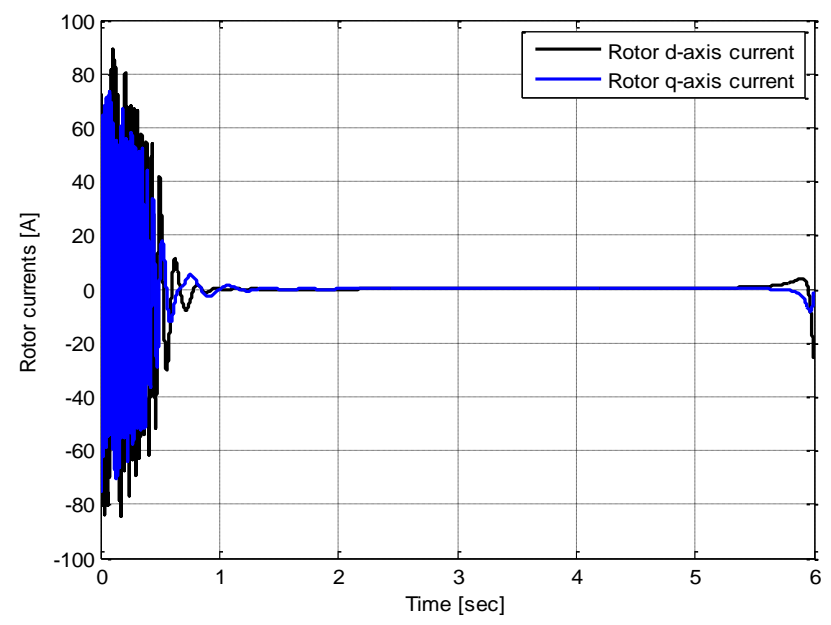

Figure 5: The SPM Rotor Current 


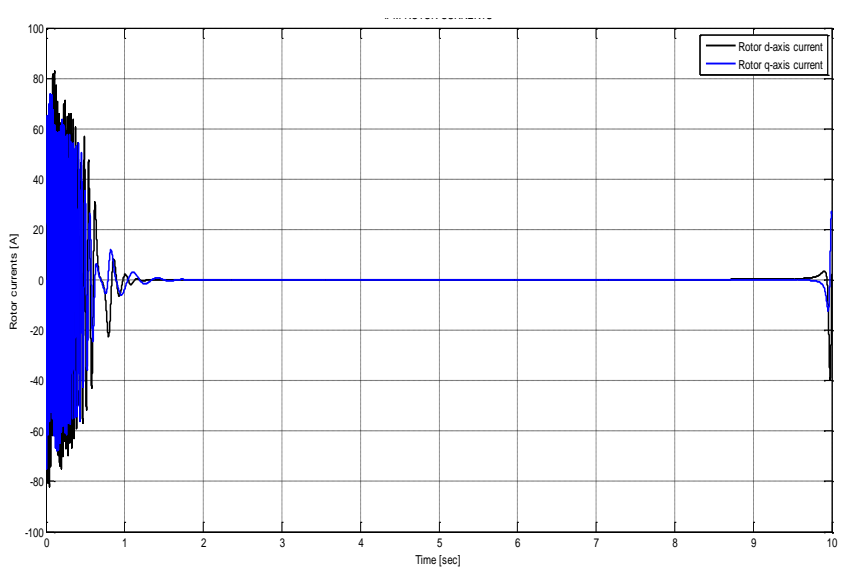

Figure 6: The IPM Rotor Current
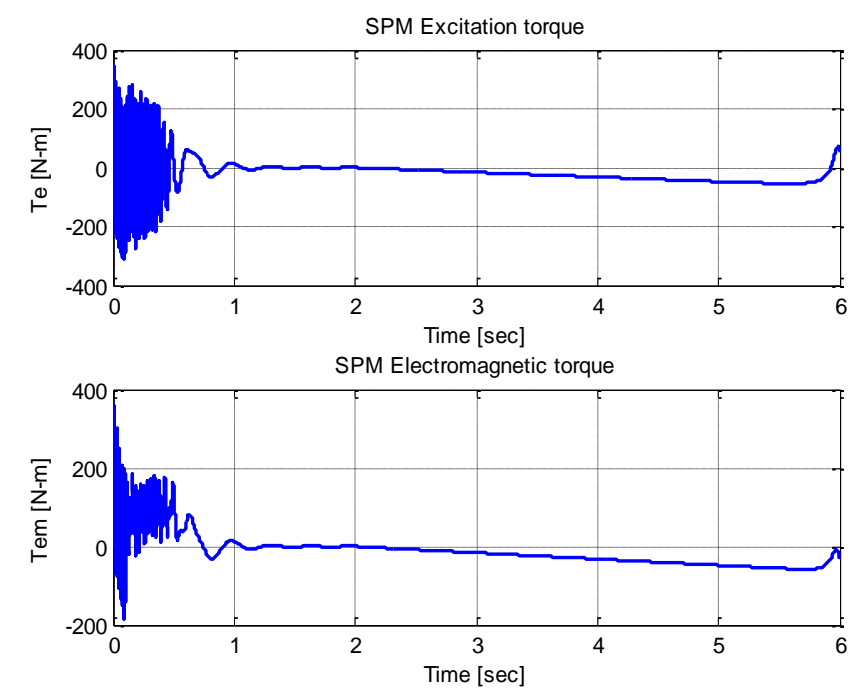

On the other hand, the surface type generates a larger permanent magnet alignment torque from the higher flux density. Instead of the loading capability at steady state, in order to compare the efficiencies of the two LSPMMs designs, the steady stator winding currents of the two LSPMMs are respectively simulated as shown in synchronous rotation with identical loads. The steady-state currents are minimal in both cases of SPM and IPM.

Figure 7a: The SPM \& IPM Excitation and Electromagnetic Torque
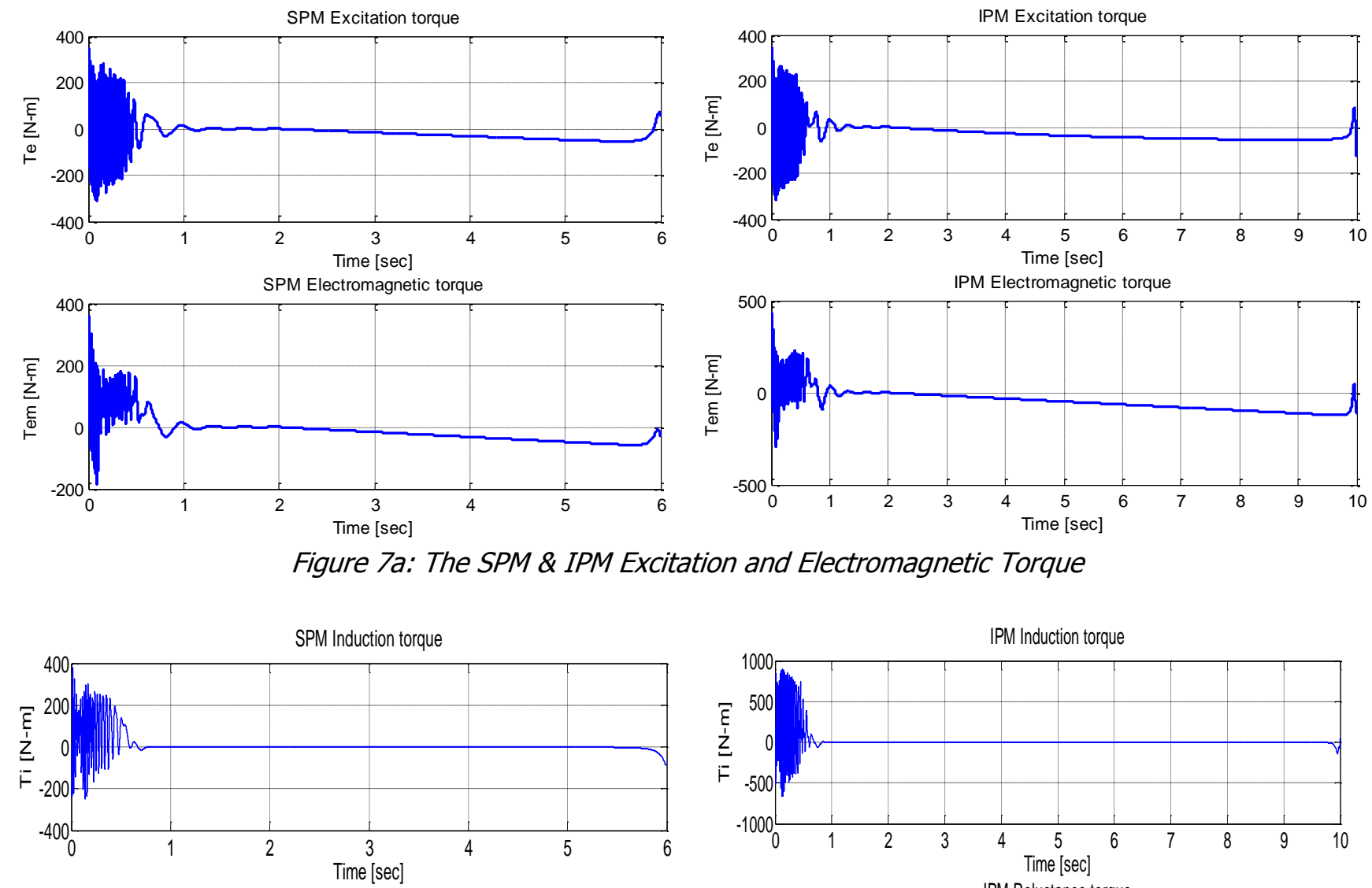

SPM Reluctance torque
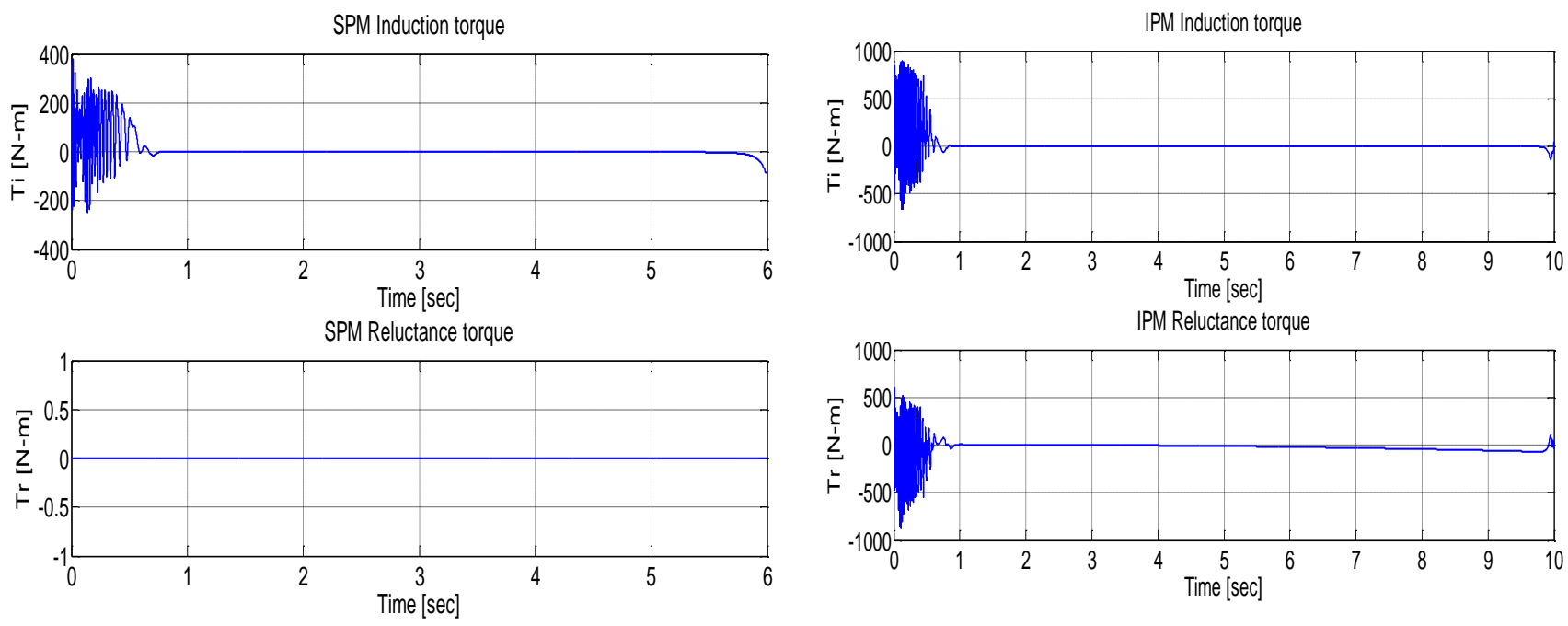

Figure 7b: The SPM \& IPM Induction and Reluctance Torque 

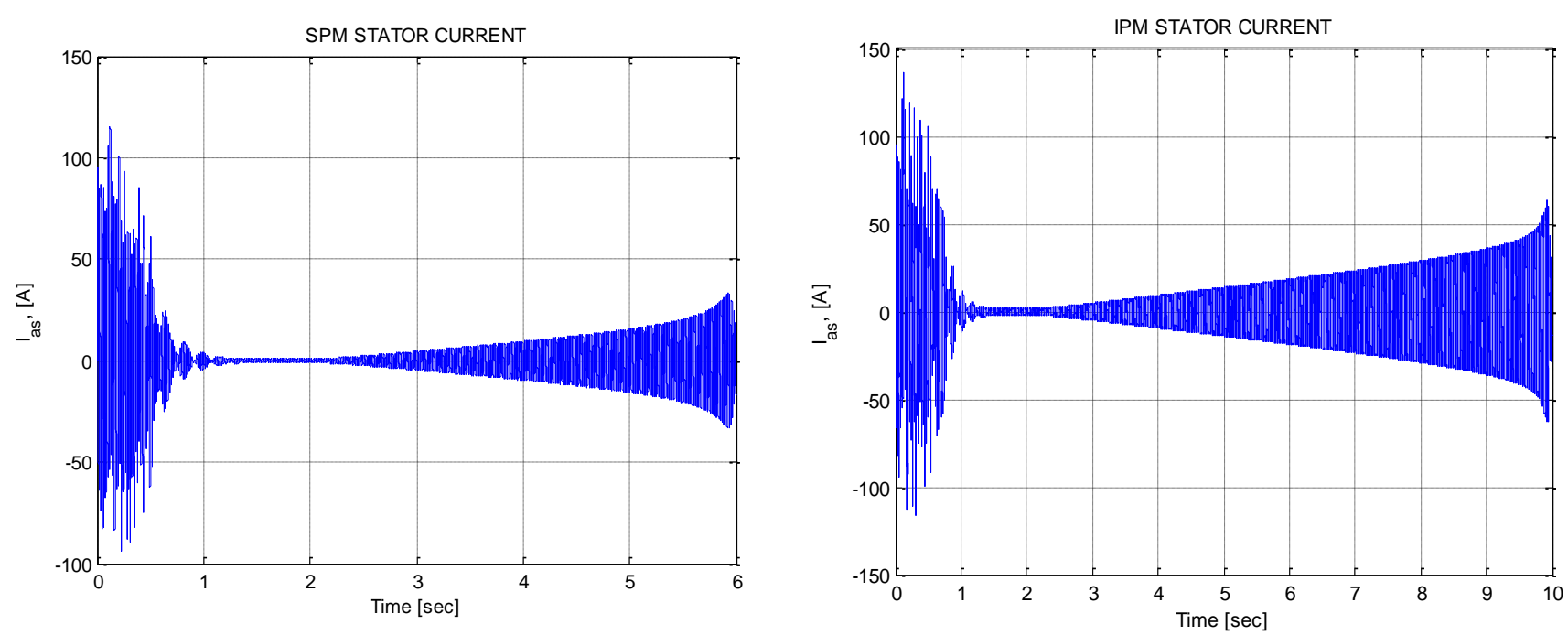

Figure 8: The IPM \& SPM Stator Currents

Since the interior magnet design has a larger synchronous reluctance torque at the synchronous speed, the steady-state current that needs to be provided to rotate the rotor of the interior type is smaller than that of the surface type at the same loading. The smaller steady-state current indicates that the interior type one uses a lower input power but reaches the same output power as the surface type; in other words, the interior type has a higher efficiency.

As the machines are loaded in both cases, stator current progressively increases with load as shown in Figure 8, lesser current is utilized in the IPM since it is known to have less flux leakage and copper losses at synchronous operation than in the SPM.

Since both machines have same parameters and attained the same input power, it can in comparative terms be verified from the peak values of the steady state stator currents of Figure 8 that the efficiency of IPM is $50 \%$ greater than the SPM.

\section{CONCLUSION}

This paper investigated the transient and steady states operations of two LSPMMs with different rotor types. The calculations showed that both designs can reach a higher efficiency than the original Induction Motors. The loading capability of the interior magnet rotor is better than the surface magnet rotor at asynchronous rotation. The interior magnet rotor had less flux leakage and copper losses at the synchronous operation under the same loading condition. The results presented here can be a reference for designing LSPMMs with fine synchronization capabilities and transient performances in the future.

\section{REFERENCES:}

[1] Bhim Singh, B. P. Singh and S. Dwivedi, "A State of Art on Different Configurations of Permanent Magnet Brushless Machines" Department of Electrical Engineering, IIT Delhi, HauzKhas, New Delhi - 110 016, Vol. 87, June 2006.

[2] M. F. Rahman, L. Zhong, M. E. Haque, and M. A. Rahman, "A direct torque controlled interior permanent magnet synchronous motor drive without a speed sensor," IEEE Trans. Energy Conversion, vol. 18, no. 1, pp. 17-22, Mar. 2003.

[3] P Pillay. "Performance and Design of Permanent Magnet AC Motor Drives". Tutorial Course Presented in IEEE Industrial Application Society Conference, San-Diego, 1989.

[4] M. A. Rahman and A. M. Osheiba, "Performance of a Large Line-Start Permanent Magnet Synchronous Motor," IEEE Trans. Energy Conversion, Vol. 5, No. 1, pp. 211-217, 1990.

[5] B. R. Teare, "Theory of hysteresis motor torque," AIEE Trans., vol. 59, no. 12, pp. 907-912, 1940.

[6] P. L. Alger and J. H. Wray, "Double and Triple Squirrel Cages for Polyphase Induction Motors" Transactions of AIEEE part III: Power Apparatus and Systems, Vol. 72, No 2, pp. 903-912, 1953

[7] M. A. Rahman, "Field Analysis of PolyphaseHysteresis Motor ", IEEE Transactions of Power Apparatus and Systems, PAS-99 (3), pp. 1164-1171, 1980.

[8] M. A. Rahman, "Steady-State Performance Analysis of PolyphaseHysteresis-Reluctance Motors ", IEEE Transactions on Industry 
Applications, Vol IA 21 (3), pp. 659-663, 1985.

[9] F. W. Merrill, "Permanent magnet excited synchronous motors," AIEE Trans., Vol. 74, no. 2, pp. 1754-1760, 1955.

[10] K. J. Binns, W. R. Barnard, M. A. Jabbar, "Hybrid permanent-magnet synchronous motors" Proceedings of IEE, Vol. 125 (3), pp. 203 - 20, 1978.

[11] M. A. Rahman, "Run-up performance of permanent magnet motors using NdBFe materials", Magnetics Conference, pp. 7-11, 1989.

[12] M. A. Rahman, T. Little and G. R. Slemon, "Analytical models for interior-type permanent magnet synchronous motors", IEEE Transactions on Magnetics, Vol. 21 (5), pp. 1741 - 1743, 1985.

[13] T, M Jahns, "Flux-Weakening Regime Operation of an Interior Permanent-Magnet Synchronous Motor Drive ", IEEE Transactions on Industry Applications, Vol. 23, (4), pp. 681 - 689, 1987.

[14] T. Sebastiangordon, G. R. Slemon "Operating Limits of Inverter-Driven Permanent Magnet Motor Drives", IEEE Transactions on Industry Applications, Vol. IA 32, No. 2, pp 327 - 333, 1987.
[15] G. Pellegrino, A. Vagati, P. Guglielmi, and B. Boazzo, "Performance Comparison Between Surface-Mounted and Interior PM Motor Drives for Electric Vehicle Application" IEEE Transactions on Industrial Electronics, Vol 59, No. 2 , pp. 803 - 811, 2012.

[16] M. A. Rahman, Z. Ping, "Field-based analysis for permanent magnet motors", IEEE Transactions on Magnetics, Vol. 30, Issue: 5 , Part: 2, pp. 3664 - 3667, 1994.

[17] L. Wang, R. D. Lorenz, "Sensorless control of permanentmagnet synchronous motor", Proceedings of Third International Conference on Power Electronics and Motion Control. Vol.1, pp. 186 - 190. 2000.

[18] J. Ji-Hoon, H. Jung-Ik, S. Seung-Ki, "Vector control of surface mounted permanent magnet motor without any rotational transducer", IEEE Sixteenth Annual Applied Power Electronics Conference and Exposition, APEC Vol. 2, pp. 845 - 849. 2001.

[19] M. N. Uddin, T. S. Radwan and M. A. Rahman, "Performance of interior permanent magnet motor drive over wide speed range", IEEE Transactions on Energy Conversion, Vol. 17 (1), pp. $79-84,2002$.

[20] Matlab Simulink ${ }^{\circledR}$, Philadelphia, PA: Mathworks, 2011. 